\title{
Emphysematous cystitis with bilateral pyelonephritis in a pediatric patient with COVID-19
}

\author{
Brent Liu Cao (1) , ${ }^{1}$ Owen Brewer, ${ }^{1,2}$ Adam R Cross ${ }^{1}$
}

'Department of Pediatrics, University of Illinois College of Medicine at Peoria, Peoria, Illinois, USA

${ }^{2}$ Department of Emergency Medicine, University of Illinois College of Medicine at Peoria, Peoria, Illinois, USA

\section{Correspondence to}

Brent Liu Cao; bcao9@uic.edu

Accepted 31 December 2021

Check for updates

(c) BMJ Publishing Group Limited 2022. No commercial re-use. See rights and permissions. Published by BMJ.

\begin{tabular}{l}
\hline To cite: Cao BL, Brewer O, \\
Cross AR. BMJ Case \\
Rep 2022;15:e245779. \\
doi:10.1136/bcr-2021- \\
245779 \\
\hline
\end{tabular}

\section{SUMMARY}

A 15-year-old female adolescent with a medical history of recurrent urinary tract infections and grade 1 leftsided vesicoureteral reflux presented to the emergency room with abdominal and back pain. Labs revealed a haemoglobin $\mathrm{A} 1 \mathrm{c}(\mathrm{HbA} 1 \mathrm{c})$ of $9.1 \%$ and a random blood glucose of $200 \mathrm{mg} / \mathrm{dL}$, consistent with new-onset diabetes mellitus. Nasopharyngeal COVID-19 PCR test returned positive. A CT scan of the abdomen and pelvis revealed bilateral attenuation of the kidneys and air in the bladder, which was confirmed by pelvic ultrasound. Gas subsequently resolved 2 days later after treatment with antibiotics, and a diagnosis of emphysematous cystitis was made. Emphysematous cystitis in the paediatric population is an extremely rare condition with four cases reported in the literature. Furthermore, there has been a reported association between COVID-19, cystitis and non-typical course of urinary symptoms. Local inflammation obstructing transportation of formed gas is one of the proposed mechanisms underlying emphysematous cystitis, and so COVID-19 may be yet another predisposing factor.

\section{BACKGROUND}

Emphysematous cystitis is an infection of the bladder associated with gas formation, with common infectious agents being Escherichia coli or Klebsiella pneumoniae. ${ }^{1}$ Diabetes mellitus and urinary tract obstruction are two of the biggest risk factors for emphysematous urinary tract infections, and cases are often complicated by serious underlying pathologies. The most commonly affected patients are elderly, immunocompromised women. Diagnosis is usually confirmed through imaging. ${ }^{2}$

The exact pathogenesis is poorly understood. A glucose-rich environment may contribute to gasproducing microbe proliferation. ${ }^{3}$ In addition, there is typically impaired transportation of the formed gas due to either anatomical obstructions or to local inflammation. ${ }^{4}$ Furthermore, the literature suggests a relationship between COVID-19 and cystitis, but the mechanism remains unclear, ranging from COVID-19-induced cytokine production to ACE2 receptor interactions in the bladder and kidneys. ${ }^{56}$ This reported COVID-19-associated cystitis may be complicated by urinary tract infections and other comorbidities that exacerbate inflammation and infection. $^{6}$

\section{CASE PRESENTATION}

A 15 -year-old female adolescent with a medical history of urinary tract infections, left ureteral reflux and a family history of type 1 diabetes initially presented to urgent care for right flank pain. She reported diffuse abdominal pain for about 1 month with worsening pain, radiation to the right flank, nausea and vomiting. She denied pneumaturia. Patient denied other symptoms and was afebrile. Physical exam revealed significant right costovertebral angle tenderness.

Her left ureteral reflux was diagnosed at 5 years of age and was grade 1 . The patient also has a history of smoke exposure and a lack of toilet paper at her step-parent's home, for which she has had to drip-dry. She had multiple prior urinary tract infections (UTIs) in the past according to her mom. Following some lifestyle changes, the patient's UTIs had resolved until this event.

\section{INVESTIGATIONS}

The patient was afebrile at the time of presentation and remained afebrile during the entire hospitalisation despite other evidence of significant systemic inflammation including a C-reactive protein of $22.4 \mathrm{mg} / \mathrm{dL}$ and a white blood cell count of 17 $400 / \mathrm{mcL}$ with $74 \%$ neutrophils. Blood culture and metagenomic next-generation sequencing (mNGS) were not obtained. Urinalysis showed pyuria, haematuria, bacteriuria, leucocyte esterase, nitrites, $3+$ ketones and 3+glucose. A routine COVID-19 test through nasopharyngeal swab came back positive. Point of care glucose and an $\mathrm{HbA} 1 \mathrm{c}$ were also $200 \mathrm{mg} / \mathrm{dL}$ and $9.1 \%$, respectively. A venous blood gas revealed $\mathrm{pH}$ 7.32, partial pressure of carbon dioxide in venous blood $\left(\mathrm{PVCO}_{2}\right)$ of $36 \mathrm{~mm}$ $\mathrm{Hg}$, partial pressure of oxygen in venous blood $\left(\mathrm{PVO}_{2}\right)$ of $72 \mathrm{~mm} \mathrm{Hg}$, bicarbonate $18.5 \mathrm{mmol} / \mathrm{L}$, $\mathrm{CO}_{2} 20 \mathrm{mmol} / \mathrm{L}$ and a base deficit of -6.9 . Serum ketones were negative. CT scans showed gasforming cystitis (figures 1 and 2) along with bilateral attenuation suggestive of pyelonephritis. Pelvic

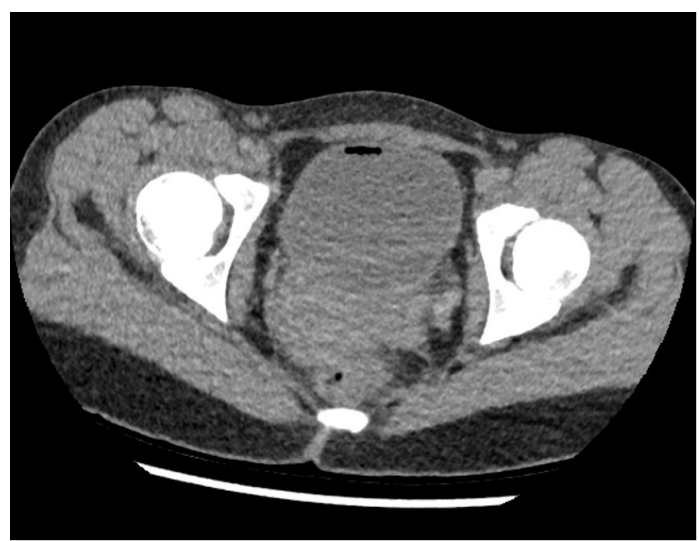

Figure 1 Axial CT scan showing gas-forming cystitis. 


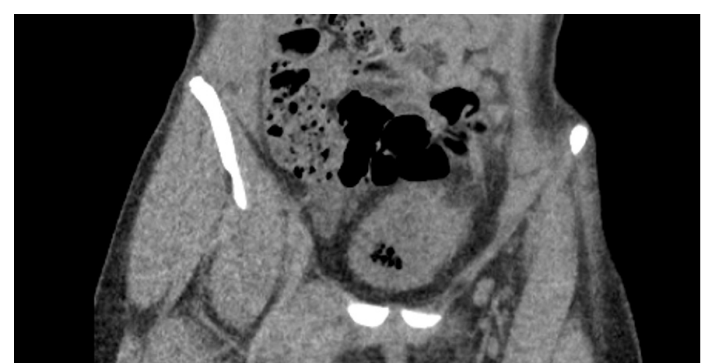

Figure 2 Coronal CT scan showing gas-forming cystitis.

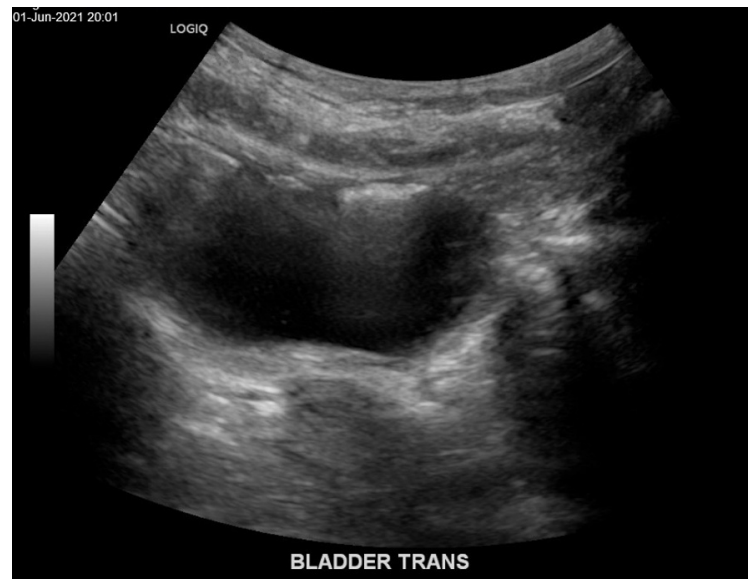

Figure 3 Pelvic ultrasound revealing increased echogenicity consistent with emphysematous cystitis.

ultrasound confirmed gas in the bladder (figure 3), with repeat ultrasound showing resolution 2 days later. Urine culture grew E. coli.

\section{DIFFERENTIAL DIAGNOSIS}

The right flank pain, costovertebral angle tenderness, positive labs and imaging findings suggested bilateral pyelonephritis. In addition, blood glucose findings, the HbA1c of 9.1\%, and positive urine glucose and ketones indicated new-onset diabetes mellitus with a state of diabetic ketoacidosis. The CT scan revealed mottled areas of increased radiolucency and a small area of complete radiolucency with an air-fluid level enclosed by the bladder wall, confirming free air within the bladder. No intraluminal air was identified (commonly described as a cobblestone or 'beaded necklace' appearance). ${ }^{78}$

The differential for emphysematous cystitis includes reflux air from a renal abscess, enterorenal fistula formation, retroperitoneal perforation, psoas abscess, or urological or radiological interventions such as catheter insertion. ${ }^{9}$ However, this patient lacked any history of trauma, medical interventions such as nephrostomy or foley insertion, and imaging did not reveal abscesses elsewhere. Characteristic imaging findings of emphysematous cystitis are air within the bladder lumen and/or wall. $^{210}$ While most cases involve gas within the bladder wall, not all cases include said imaging findings. Some studies suggest radiographic findings present $50 \%-85 \%$ of the time. ${ }^{10-12}$ Given the patient's signature risk factors such as smoke exposure and prior history of grade 1 vesicoureteral reflux, new-onset diabetes mellitus, history and imaging findings, a diagnosis of emphysematous cystitis was made. Urine culture was as expected with $E$. coli. ${ }^{1}$ In addition, the concurrent COVID-19 positivity provides another point of interest.

\section{TREATMENT}

Whereas uncomplicated cystitis can be managed with a short course of oral antibiotic in the outpatient setting, current guidelines recommend parenteral antibiotics for emphysematous cystitis, usually an empiric broad-spectrum antibiotic such as ceftriaxone. ${ }^{2}$ Emphysematous urinary tract infections are often associated with more complex and serious urinary tract disease (such as pyelonephritis), and urological consult for possible nephrectomy and addressing anatomic anomalies is advised. ${ }^{4}$ Urology consult discussed further evaluation for possible neurogenic bladder once the acute infection had resolved. This patient was treated initially with ceftriaxone; antibiotic coverage was narrowed with cefazolin on day 2 as the urine culture grew $E$. coli susceptible to first-generation cephalosporins. Parenteral antibiotics were continued for a 7-day course following the recommendations of the urology consult, then transitioned to oral cephalexin on the day of discharge with a 7-day course planned in the outpatient setting (14 days of total antibiotic therapy). The patient's diabetes was managed with insulin and intravenous fluids, and she was otherwise asymptomatic despite COVID-19 positivity.

\section{OUTCOME AND FOLLOW-UP}

After initiating antibiotic treatment and managing the patient's new-onset diabetes, the patient's right flank pain gradually resolved. Repeat pelvic ultrasound on hospital day 3 did not show findings suggestive of emphysematous cystitis. After a 7-day hospital stay, she returned home with a full recovery.

\section{DISCUSSION}

Emphysematous cystitis is a relatively rare and complicated urinary tract infection. Almost all documented emphysematous cystitis have been in adults. ${ }^{13}$ Most cases typically include complex underlying comorbidities. ${ }^{9}$ Of the four paediatric cases reported thus far, one had bilateral pelviureteric junction obstruction, one had spastic quadriplegia and pancreatitis, one with concomitant urosepsis and another presenting following a bone marrow transplant complicated by gut-associated graftversus-host disease. ${ }^{14-17}$ The key identifying features are characteristic imaging findings of gas in the bladder and/or bladder wall on CT scan and strong focal echoes on ultrasonography. Many sources indicate that radiographic detection does not necessarily need to be present in all cases, with $50 \%-85 \%$ of cases of gasforming UTIs containing such findings. Thus, diagnosis should be made with the entire clinical picture in mind. ${ }^{210-12}$

The pathogenesis for emphysematous cystitis is not well understood. Some hypothesise that high glucose levels provide an environment favourable for gas-forming organisms such as E. coli. Subsequently, urinary tract infections play a central role in the disease process, providing a mechanism by which organisms can reach the bladder. ${ }^{2}$ Shokeir et al described urinary tract obstruction being present in all their patients with emphysematous pyelonephritis without diabetes mellitus and in half of their patients with diabetes mellitus. ${ }^{4}$ Furthermore, Grupper et al discussed how inflammation may increase local pressures, impair circulation, leading to gas accumulation, additional infarction, and provide a good culture medium for gas-forming bacteria, creating a vicious cycle. ${ }^{2}$ Clinical guidelines currently recommend parenteral antibiotics followed by urology consult for possible cystectomy. ${ }^{1}$ This patient's symptoms resolved on antibiotic treatment and diabetes management, and she did not develop any characteristic COVID-19 symptoms. 
All the previously reported cases have had significant concurrent obstructive and inflammatory processes. While this patient has the signature risk factors such as type 1 diabetes and ureteral reflux, COVID-19 also has a documented history of urinary tract shedding and frequency. ${ }^{18}$ The patient's elevated HbA1c and random glucose are common findings in acutely ill patients with diabetes; however, prior studies have suggested that COVID-19 may directly infect human pancreatic beta cells, inhibiting their functioning and predisposing this patient to urinary tract infections secondary to hyperglycaemic-induced bacterial overgrowth. ${ }^{19}$ Prior research has also suggested that COVID-19 can increase urinary frequency and may be a cause of viral cystitis. ${ }^{620}$ The exact mechanism by which the virus interacts with the urinary system is not well understood but is thought to involve an increase in inflammatory cytokines released into the urine and/or directly expressed by the bladder. ${ }^{6}$ COVID-19 has a well-documented history of inducing inflammation and targeting ACE2 receptors to enter target cells. The kidneys and bladder have high and medium expressions, respectively. ${ }^{5}$ Finally, there remains the possibility that this patient's COVID-19 positivity is purely incidental, playing no role in the pathogenesis of her disease process. A general state of poor health, such as diabetes, is a known predisposing factor. ${ }^{21}$ While that is a consideration, it is important for medical professionals to stay vigilant about not only the possible complex interplay between COVID-19 and diseases of the urinary system but also about the possible underlying factors contributing to atypical presentations of urinary tract infections.

\section{Patient's perspective}

Initially I was just so overwhelmed with everything. I was used to urinary tract infections, but they always went away with antibiotics. This time the worsening back and abdominal pain had me worried. I feel much better now, but I am worried about something like this happening again in the future. (Patient)

When the doctor told me that (the patient) had diabetes and that her COVID-19 test came back positive, it was a lot to take in. I knew we had a family history of autoimmune disease, but I didn't expect to deal with so much at one time. I am glad, however, that we were able to catch her diabetes early on, and I hope that this case can help others out there. (Mother of the patient)

\section{Learning points}

- Complex presentations of urinary tract infections, such as this patient's concurrent diabetic ketoacidosis, infectious status, medical history, family history and social/environmental history warrant further diagnostic workup.

- Emphysematous cystitis is an extremely rare condition in the paediatric population even among those with characteristic predisposing factors. ${ }^{14}$ In a child with emphysematous urinary tract infections, there is almost certainly underlying anatomical abnormalities, diabetes mellitus or both.

- COVID-19 may have complex interactions with the urinary system, especially in patients with a medical history of conditions that affect or involve the urinary tract.
Contributors The authors Brent Cao, Dr. Owen Brewer, and Dr. Adam Cross all contributed to the data collection, analysis, writing, and editing of this manuscript.

Funding The authors have not declared a specific grant for this research from any funding agency in the public, commercial or not-for-profit sectors.

Competing interests None declared.

Patient consent for publication Consent obtained from parent(s)/guardian(s)

Provenance and peer review Not commissioned; externally peer reviewed.

Case reports provide a valuable learning resource for the scientific community and can indicate areas of interest for future research. They should not be used in isolation to guide treatment choices or public health policy.

\section{ORCID iD}

Brent Liu Cao http://orcid.org/0000-0002-6148-6409

\section{REFERENCES}

1 Thomas AA, Lane BR, Thomas AZ, et al. Emphysematous cystitis: a review of 135 cases. BJU Int 2007;100:17-20.

2 Grupper M, Kravtsov A, Potasman I. Emphysematous cystitis: illustrative case report and review of the literature. Medicine 2007;86:47-53.

3 Yang W-H, Shen N-C. Gas-Forming infection of the urinary tract: an investigation of fermentation as a mechanism. Journal of Urology 1990;143:960-4.

4 Shokeir AA, El-Azab M, Mohsen T, et al. Emphysematous pyelonephritis: a 15-year experience with 20 cases. Urology 1997;49:343-6.

5 Li MY LL, Zhang Y, Wang XS. Expression of the SARS-CoV-2 cell receptor gene ACE2 in a wide variety of human tissues. Infect Dis Poverty 2020;9:45.

6 Lamb LE, Dhar N, Timar R, et al. COVID-19 inflammation results in urine cytokine elevation and causes COVID-19 associated cystitis (CAC). Med Hypotheses 2020;145:110375.

7 Grayson DE, Abbott RM, Levy AD, et al. Emphysematous infections of the abdomen and pelvis: a pictorial review. RadioGraphics 2002;22:543-61.

8 Tzou K-Y, Chiang Y-T, Cystitis E. Emphysematous cystitis. N Eng/ J Med Overseas Ed 2016;375:1779.

9 Yu M, Robinson K, Siegel C, et al. Complicated genitourinary tract infections and mimics. Curr Probl Diagn Radiol 2017;46:74-83.

10 InAmy C, Weintrob DJSStephen B, Calderwood M, eds. Emphysematous urinary tract infections. Waltham, MA: Wolters Kluwer, 2021

11 Huang JJ, Tseng CC. Emphysematous pyelonephritis: clinicoradiological classification, management, prognosis, and pathogenesis. Arch Intern Med 2000;160:797-805.

12 Dekeyzer S, Houthoofd B. Emphysematous cystitis. J Belg Soc Radiol 2018;102:66.

13 Wang Q, Sun M, Ma C, et al. Emphysematous pyelonephritis and cystitis in a patient with uremia and anuria: a case report and literature review. Medicine 2018;97:e11272

14 Uhlman MA, Andresen ED, Storm DW. Pediatric emphysematous cystitis: a report and review of a rare diagnosis in children. Can J Urol 2015;22:7924-6.

15 Sharma J, Singhal J. A child with urosepsis and a bladder with a halo: answers. Pediatr Nephrol 2020;35:75-6.

16 Pringle C, Brothers E. Emphysematous cystitis following bone marrow transplant. J Pediatr Hematol Oncol 2020.

17 Fernandes LP, Sajwany MJ, Derweesh A. Emphysematous pyelonephritis and cystitis associated with bilateral pelviureteric junction obstruction: a case report. J Pediatr Surg 1998;33:739-40.

18 Kashi AH, De la Rosette J, Amini E, et al. Urinary viral shedding of COVID-19 and its clinical associations: a systematic review and meta-analysis of observational studies. Urol J 2020;17:433-41.

19 Wu C-T, Lidsky PV, Xiao Y, et al. SARS-CoV-2 infects human pancreatic $\beta$ cells and elicits $\beta$ cell impairment. Cell Metab 2021;33:1565-76.

20 Mumm J-N, Osterman A, Ruzicka M, et al. Urinary frequency as a possibly overlooked symptom in COVID-19 patients: does SARS-CoV-2 cause viral cystitis? Eur Urol 2020;78:624-8.

21 Wolff D, Nee S, Hickey NS, et al. Risk factors for Covid-19 severity and fatality: a structured literature review. Infection 2021;49:15-28. 
Copyright 2022 BMJ Publishing Group. All rights reserved. For permission to reuse any of this content visit https://www.bmj.com/company/products-services/rights-and-licensing/permissions/

BMJ Case Report Fellows may re-use this article for personal use and teaching without any further permission.

Become a Fellow of BMJ Case Reports today and you can:

- Submit as many cases as you like

- Enjoy fast sympathetic peer review and rapid publication of accepted articles

- Access all the published articles

Re-use any of the published material for personal use and teaching without further permission

Customer Service

If you have any further queries about your subscription, please contact our customer services team on +44 (0) 2071111105 or via email at support@bmj.com.

Visit casereports.bmj.com for more articles like this and to become a Fellow 